\title{
The effects of moratoriums on hotel building: An anti-tourism measure, or rather protection for local incumbents?
}

\author{
Germà Bel $^{\dagger \varphi}$, Stephan Joseph ${ }^{\dagger} \&$ Ferran A. Mazaira-Font ${ }^{\dagger}$ \\ ${ }^{\dagger}$ Universitat de Barcelona \\ (Forthcoming in Applied Economics Letters)
}

甲 Corresponding author: Germà Bel. ORCID ID: 0000-0002-1330-8085

Contact address (all authors): Department of Econometrics, Statistics and Applied Economics - Universitat de Barcelona. C/ John Keynes 1-11, 08034 Barcelona, Spain. E-mail: gbel@ub.edu ; stephanjoseph4989@gmail.com ; fmazaifo7@ alumnes.ub.edu

\begin{abstract}
In July 2015 the newly elected City Council of Barcelona approved a moratorium on the building of hotels. This study empirically evaluates its effect on hotel prices, using 202,019 daily observations on hotel prices between 2011 and 2017 . While the inflow of tourists continued to rise after the moratorium, our synthetic control method finds that hotel prices increased significantly above pre-intervention trends. This suggests that the actual outcome of the moratorium was the protection and promotion of the interests of local industry incumbents.
\end{abstract}

Keywords: Rent-seeking; Hotel pricing; Tourism; Synthetic control

JEL-Codes: L43, L51, L83, R52 


\section{Introduction}

Concerns about sustainability of tourism growth were on the rise in the most visited tourist destinations in the last years. Even if the COVID crisis may have palliated transitorily that debate, given of it particularly strong effects on tourism activities (Bel, Gasulla and Mazaira-Font, 2021), it is likely to make a comeback in the future, because of the pressures from growth of tourism on the environment, urban residential patterns, and public services. Being Barcelona among the top touristic destinations in the world, sustainability of tourism growth in the city provoked intense social debate and scholarly research in the last decade (see Gutiérrez et al, 2017; Rico et al., 2019 Cocola-Gant and Lopez-Gay, 2020; Pirillo Ramos and Mundet, 2021).

Claiming concern about the negative effects of mass tourism on the city's residents, the City Council of Barcelona approved a moratorium on the construction of new hotels effective 1 July 2015 . From then on, only projects underway before the moratorium could continue (though facing delays) and no new hotel licenses were to be granted. Anti-tourism interest groups strongly supported the moratorium. Interestingly, the Gremi d'Hotels de Barcelona (the major local pro-hotel lobby) warmly welcomed the moratorium, as shown by her press statement issued in October 2015: "It is expected that this moratorium will serve to firmly confront illegal tourist accommodation establishments, the main protagonists of the effects suffered by residents; that will allow planning the sustainable growth of the sector and preserving the essence that makes it [Barcelona] attractive to visitors, and will pave the way for an analysis of the tourist accommodation load in the different areas of Barcelona" (GHB, 2015).

At the end of March 2017 the new Local Plan for Tourist Accommodation was passed and came into effect; this plan was later suspended by the Judiciary, and the City Council has since kept the restrictive policy in place. 
Following the moratorium, the rate of growth in the number of hotels fell by some $60 \%$, from 5.3\% in 2015 to 2.2\% in 2017 (Gremi d'Hotels de Barcelona Annual Reports). However, the tourist inflow continued to increase at the same pace as before, until the terror attack of 17 August (City Statistics). According to the City Council, average hotel prices rose by $16.9 \%$ between 2015 and 2017 .

Stigler (1971) claimed that, to protect and foster their private interests, industrial sectors would prefer barriers to entry over any other type of government intervention; this policy limits competition and subsequently increases prices. Later, Becker (1983) elaborated on the competition between pressure groups for political influence. Specifically applied to the hotel industry, Hernández-Martín et al. (2015) warned that hotel moratorium will usually have as a primary effect to increase price and profitability of market incumbents, thus being a potential rent-seeking device.

The research question we address here is whether the moratorium had a relevant effect on decreasing tourism influx or basically restricted competition thus increasing profitability for local incumbents. We conduct a synthetic control study to analyse whether this increase in prices was related to the moratorium and its effects. In this way, we check whether barriers of entry resulted in effective protection of the local incumbent industry. Our results suggest that this was the main result.

\section{Data and sources}

Data used for this study comprise the historical records of average daily prices of 85 European cities including Barcelona (list of cities in table 1), with at least 330,000 inhabitants and with no prohibitions applied during the period of analysis (1 January 2011 to 1 August 2017).

(Table 1 here) 
The average price is calculated as the average daily price of the bookings of double rooms of 3- and 4-star hotels made at Booking.com. Due to the privacy policy of Booking.com, the prices have been indexed by city to 100 . In all, we were able to use 202,019 observations.

We restrict the analysis until August 2017 for two reasons. First, Barcelona suffered a terrorist attack on 17 August 2017, in which 15 people were killed, most of them tourists. Second, Barcelona suffered an additional demand shock in autumn 2017, with the Independence Referendum held on 1 October, followed by the Catalan parliament's Declaration of Independence on 27 October. The next day the Spanish government took over the regional institutions, ushering in a period of political instability.

\section{Empirical strategy}

We aim to assess the impact on hotel prices of the moratorium on the construction of new hotels approved by the City Council. The last-twelve-month average price of hotel bookings in Barcelona rose by $16 \%$ in the post-treatment period, from $109.96 €$ to 127.47€, while for the rest of the cities it grew by $2 \%$, from $101.24 €$ to $103.50 €$. However, the comparison may be misleading, because the pricing behaviour in Barcelona is quite different from the average (Figure 1).

Figure 1 here

To estimate the impact of the prohibition, we build a counterfactual using the synthetic control method (Abadie and Gardeazábal, 2003; Abadie, Diamond, and Hainmueller 2010). Given a sample of N+1 units, among which one is the unit of study and the rest are potential comparisons (donor pool), the synthetic control is defined as the weighted average of the donors that best reproduce the treated unit in terms of a set of pre-intervention characteristics (covariates). 
Specifically, given $X_{1}$ a $(k \times 1)$ vector of preintervention covariates of the treated and $X_{0}$ the $k \times N$ matrix containing the values of these variables for all the donor pool, the optimal weights for the synthetic control correspond to the vector $\mathrm{W}^{*}$ that minimizes $\sum_{m=1}^{k} v_{m}\left(X_{1 m}-X_{0 m} W\right)^{2}$, where $v_{m}$ represents the relative importance of the $m$-th variable.

Let $Y_{j t}$ be the outcome of unit $j$ at time $t$. The comparison of postintervention outcomes between the treated unit and the synthetic control, $Y_{1}-Y_{0} W^{*}$, gives the estimation of the effect of the treatment.

\section{Results}

The synthetic control for Barcelona built with all the donor pool consists of seven cities, whose weights are: $32.3 \%, 27.6 \%, 17.6 \%, 15.3 \%, 4.4 \%, 2.6 \%$, and $0.3 \%$. The mean absolute prediction error in the pre-treatment period is $2.14 \%$. Due to data confidentiality constraints, the names of the cities in the pool were not provided by Booking, which makes it impossible to link cities and covariates. Hence, we could only build a synthetic control using historical prices as covariates.

This may lead to interpolation biases (Abadie and Gardeazábal, 2003), as the similarity of the counterfactual with respect to the treated unit is based only on the correlation between them before the treatment. To mitigate this effect, we build an alternative estimation of the counterfactual by limiting the donor pool to 26 cities in Mediterranean countries (list of cities available upon request), which share a set of common cultural traits, further to geographic proximity.

Restricting the donor pool to Mediterranean countries, the counterfactual reduces to five cities, whose weights are: $34.0 \%, 31.4 \%, 16.7 \%, 14.8 \%$, and $3.2 \%$. The MAPE is $2.19 \%$. Remarkably, five out of the seven cities of the synthetic with all the donor pool belong to Mediterranean countries, and the two counterfactuals share four 
cities in common, which account for $92.7 \%$ and $96.8 \%$ of the total weights, respectively. The cities whose weights in the unrestricted synthetic were $32.3 \%, 27.6 \%$, $17.6 \%$, and $15.3 \%$, obtain $31.4 \%, 34.0 \%, 16.7 \%$, and $14.8 \%$ in the restricted one. These results show that the risk of interpolation bias is low, since both the restricted and unrestricted synthetic methods built almost the same counterfactual. Thus, only cities with similar covariates (belonging to Mediterranean countries) exhibit similar patterns to Barcelona.

Figure 2 presents the difference in price evolution between Barcelona and the two counterfactuals, before and after the treatment. After the intervention, the price in Barcelona increased with respect to the counterfactual, reaching a maximum difference of 34 points in the summer of 2017. The difference in price was affected by seasonality, reaching yearly peaks in summer. This is consistent with the fact that the less competitive the market, the higher the expected price increase in case of a supply disruption (Kalnins, 2006). Hence, in summer, when hotel occupancy rates in Barcelona are above $80 \%$, a disruption in the offer leads to a much higher price increase than in the rest of the year. The pricing gap between the most expensive month and the cheapest one rose from an average of 30.2 percentage points before the moratorium to 47.4 points two years later. Actually, during the post-treatment, Barcelona had the fourth largest increase in average monthly price volatility (out of 85 cities).

Figure 2 here

\section{Robustness checks}

As a robustness check of our estimation, we conduct two placebo tests. First, in a placebo test in time, we calculate the estimated impact had the intervention been applied two years before. As there was no intervention, we expect the impact to be near zero. We apply the method restricted to Mediterranean countries. Figure 3 shows that there is 
no significant impact in price evolution when we assume the intervention was in July 2013.

Figure 3 here

Second, we perform a placebo test in space. We consider all the cities in the donor pool and calculate the estimated impact had the intervention been applied to them in July 2015. We expect the impact to be near zero. We apply the method only to cities where the MAPE of the counterfactual in the pre-intervention period is $3 \%$ or lower, to ensure a proper fitting and the validity of the methodology. Figure 4 shows that the impact estimated for Barcelona is consistently higher than that estimated for the placebo cities, which is near zero. On average, placebo cities deviated 2.7 indexed price points with respect to the counterfactual during the post-intervention period (range -4.2 to 12.8 ). Barcelona deviated 16.0 points.

Figure 4 here

\section{Discussion and conclusion}

The city council of Barcelona approved a moratorium on hotels building in July 2015. The moratorium was supported by anti-tourist grassroot activists, and also for the main local pro-hotel lobby. Although the policy was designed to reduce tourism, the numbers of tourists in the city continued to grow in the following years.

We have evaluated the effect on prices of the moratorium on the construction of hotels by means of a synthetic control analysis. In fact, the most visible effect was a sharp increase in prices imposed by the local incumbent industry. While our empirical strategy does not allow for claiming a causal inference, we believe that other factors that could potentially explain such a sharp increase in prices were not at play. First, we find that cumulative CPI July 2015-2017 in Spain was 0.9\%, well below that in the Euro Zone (almost 2\%). One of the reasons for lower CPI increases in Spain was the internal 
devaluation policy implemented after the Great Recession, which had particularly important effects in private sector salaries with a high rate of temporary contracts, such as the hotel industry. Hence, we would expect inflation being ever lower in hotel industry. Second, demand for hotel accommodation did not experience a significant increase during 2015-2017 (6.2\%. according to City Statistics) while it increased by $7.7 \%$ in the EU. Therefore, there is no evidence that other competing factors can help to explain the price increase in Barcelona.

The local incumbent hotel industry, who had warmly welcomed the measure when it was passed, eventually reaped tangible profits from this policy intervention. Thus, barriers of entry worked in the way they are expected to: by limiting competition, they allowed important price increases. From our analysis a relevant implication emerges: Those governments concerned with problems derived from excess tourism should avoid measures that discriminate between industry players. These last have been shown to translate into increased private profits, rather than into effective tourism containment.

Policy makers and destination managers concerned with the sustainability of tourism growth and its associated negative externalities, such as pollution and congestion (Chang, Lu and Shih-Wen, 2011), housing price increase (Biagi, Brandano and Lambini, 2015), and crime increase (Biagi and Detotto, 2014), can explore other alternative measures that focus on the compensation of externalities rather than discriminating between incumbents and challengers.

For instance, introducing or increasing tourist lodging taxation. The city of Barcelona increased the tourist tax from around one $€$ in 2017 up to three $€$ in 2021 (depending on lodging categories), and the tax will increase to four $€$ in 2022. Also, tax surcharges on high season touristic transportation and the promotion of more 
environmentally friendly transportation practices could be considered. This would usually require intergovernmental coordination, because often the main transportation facilities are in municipalities other than the destination, and supra-municipal governments are responsible for setting airport and port fees. This type of measures has additional advantages: they can be fine-tuned with respect to targets in the volume and type of tourism received. Furthermore, they can generate revenues that can be used by local governments to compensate for the pressures from tourism on public services.

\section{References}

Abadie, A., and J. Gardeazábal. 2003. "The Economic Costs of Conflict: A Case Study of the Basque Country." American Economic Review 93(1), 113-132.

Abadie, A., A. Diamond and J. Hainmueller. 2010. "Synthetic control methods for comparative case studies: Estimating the effect of California's tobacco control program.” Journal of the America Statistical Association 105(490), 493-505.

Becker, G.S. 1983. “A Theory of Competition Among Pressure Groups for Political Influence.” Quarterly Journal of Economics 98(3), 371-400.

Bel, A., Ó Gasulla and F.A. Mazaira-Font. 2021. "The effect of health and economic costs on governments' policy responses to COVID-19 crisis under incomplete information." Public Administration Review forthcoming

Biagi, B, M. Brandano, and D. Lambini. 2015. "Does tourism affect housing prices? Evidence from Italy." Growth and Change 46(3), 501-528.

Biagi B. and C. Detotto, 2014. "Crime as Tourism Externality.” Regional Studies 48(4), 693-709.

Chang J.J, L.J. Lu and H. Shih-Wen. 2011. "Congestion Externalities of Tourism, Dutch Disease and Optimal Taxation: Macroeconomic Implications.” Economic Record 87(276), 90-108. 
Cocola-Gant A. and A. Lopez-Gay. 2020. "Transnational gentrification, tourism and the formation of 'foreign only' enclaves in Barcelona.” Urban Studies 57(15), 30253043.

GHB. (2015). Suspensión de tramitación y licencias de alojamiento turístico. Barcelona: Gremi d'Hotels de Barcelona. Press Statement October 2015. http://www.barcelonahotels.org/ca/detall/1075/58 (downloaded 2 May 2021)

Gutiérrez, J., J.C. García-Palomares, G. Romanillos, and M-H. Salas-Olmedo. 2017. "The eruption of Airbnb in tourist cities: Comparing spatial patterns of hotels and peer-to-peer accommodation in Barcelona.” Tourism Management 62, 278-291.

Hernández-Martín, R., C.D. Álvarez-Albelo and N. Padrón-Fumero. 2015. "The economics and implications of moratoria on tourism accommodation development as a rejuvenation tool in mature tourism destinations." Journal of Sustainable Tourism 23(6), 881-899.

Kalnins, A. 2006. "The U.S. Lodging Industry.” Journal of Economic Perspectives 20(4), 203-218.

Pirillo Ramos, S. and L. Mundet. 2021. "Tourism-phobia in Barcelona: dismantling discursive strategies and power games in the construction of a sustainable tourist city." Journal of Tourism and Cultural Change 19(1), 113-131.

Rico, A., J. Martínez-Blanco, M. Montlleó, G. Rodríguez, N. Tavares, A. Arias, and j. Oliver-Solà. 2019. "Carbon footprint of tourism in Barcelona," Tourism Management 70, 491-504.

Stigler, G.J. 1971. "The theory of economic regulation." Bell Journal of Economics and Management Science 2(1), 3-21. 
Table 1: Cities considered as potential donors

\begin{tabular}{|l|l|l|l|}
\hline Alicante & Coventry & Lisbon & Rome \\
\hline Amsterdam & Dortmund & Liverpool & Rotterdam \\
\hline Antwerp & Dresden & Lódź & Seville \\
\hline Athens & Dublin & London & Sheffield \\
\hline Berlin & Duisburg & Lyon & Sofia \\
\hline Bilbao & Düsseldorf & Madrid & Stockholm \\
\hline Birmingham & Edinburgh & Málaga & Stuttgart \\
\hline Bochum & Essen & Manchester & Szczecin \\
\hline Bologna & Florence & Marseille & Tallinn \\
\hline Bradford & Frankfurt & Milan & The Hague \\
\hline Bratislava & Gdańsk & Munich & Toulouse \\
\hline Bremen & Genoa & Murcia & Turin \\
\hline Bristol & Glasgow & Naples & Utrecht \\
\hline Brno & Gothenburg & Nice & Valencia \\
\hline Brussels & Hamburg & Nuremberg & Vienna \\
\hline Bucharest & Hanover & Palermo & Vilnius \\
\hline Budapest & Helsinki & Palma de Mallorca & Warsaw \\
\hline Bydgoszcz & Kraków & Paris & Wroclaw \\
\hline Cardiff & Las Palmas & Poznań & Wuppertal \\
\hline Cologne & Leeds & Prague & Zagreb \\
\hline Copenhagen & Leipzig & Riga & Zaragoza \\
\hline
\end{tabular}

Source: Authors 


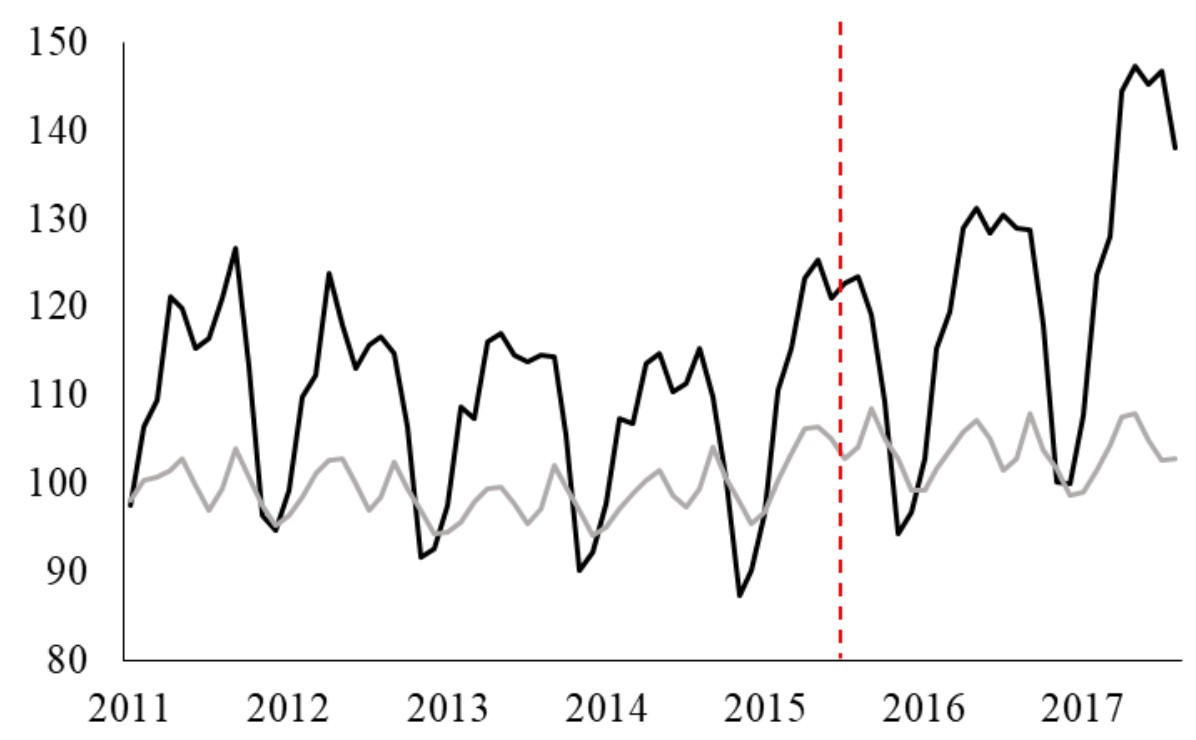

Figure 1- Average price in Barcelona (black) and the rest of European cities (grey). Vertical dashed line: intervention (July 2015) 


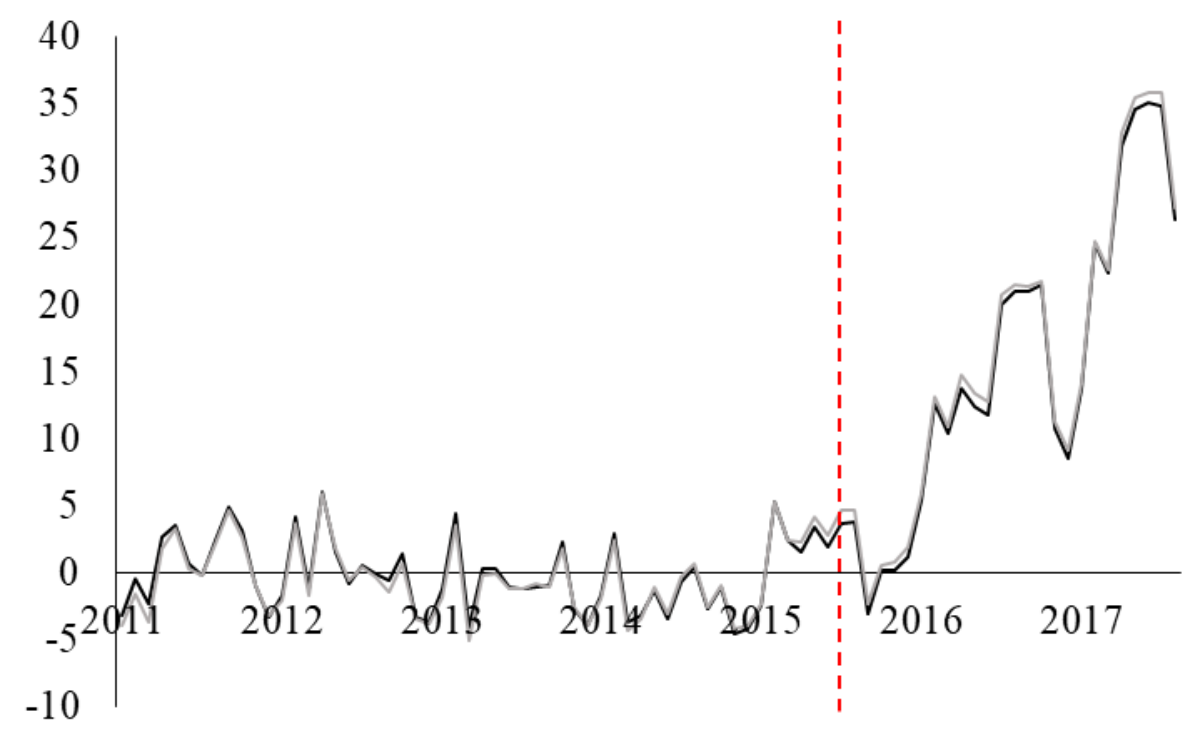

Figure 2- Difference in the indexed average price evolution between Barcelona and the unrestricted synthetic control (black) and the control restricted to Mediterranean countries (grey). Vertical dashed line: intervention (July 2015) 


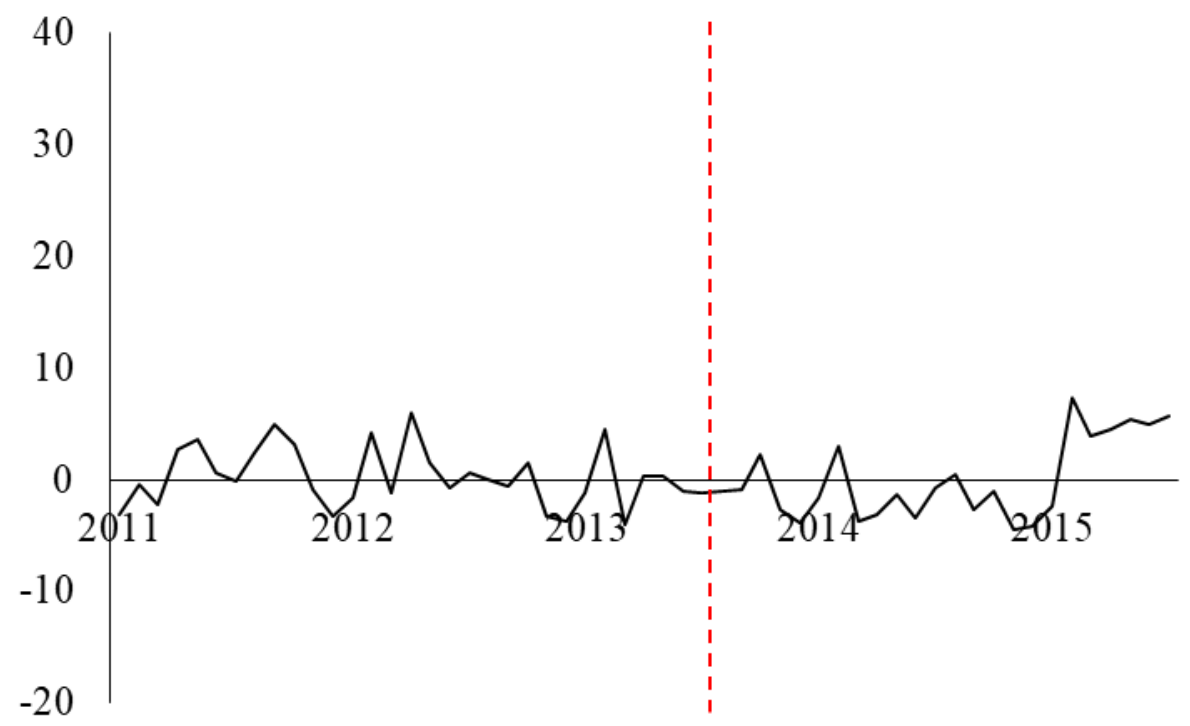

Figure 3- Placebo test in time. Price difference between Barcelona and the counterfactual. 


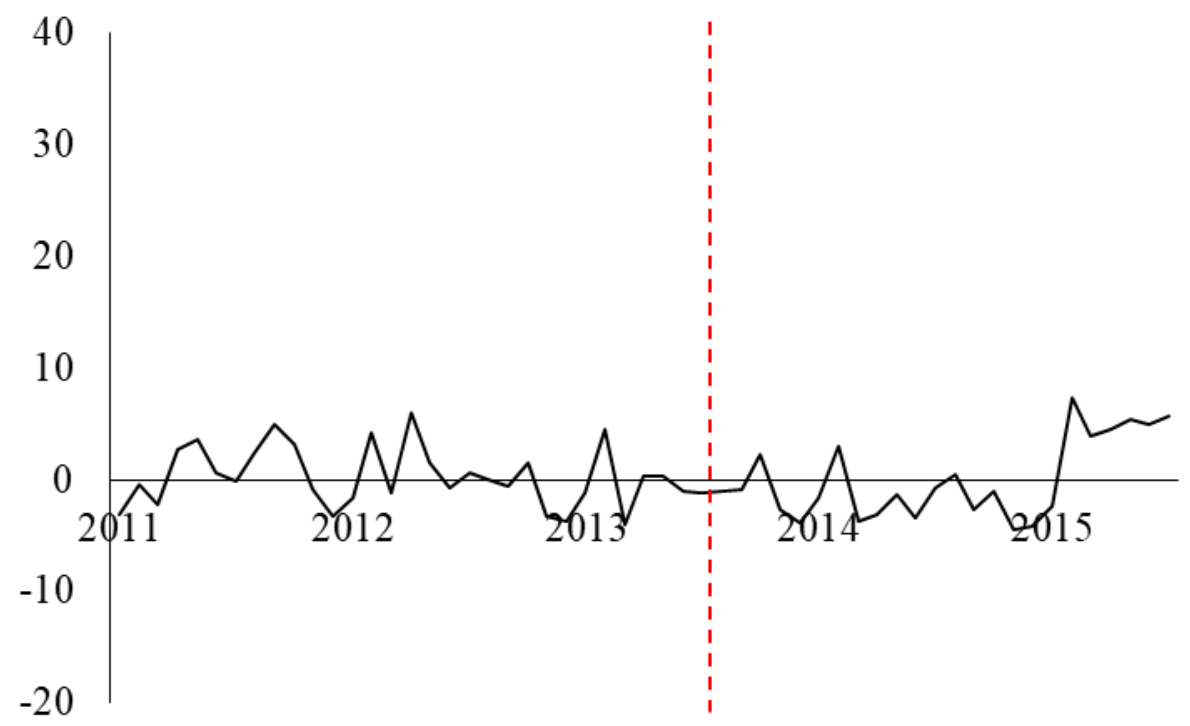

Figure 3- Placebo test in time. Price difference between Barcelona and the counterfactual. 